\title{
Diversity Beyond Demographics: Environmental Worldviews of Forestry and Natural Resource Undergraduate Students
}

\author{
Sativa Cruz ${ }^{1}$, Chelsea Batavia ${ }^{1}$, Ana Spalding $^{2}$, Ivan Arismendi $^{3}$, and Michael Nelson ${ }^{1}$ \\ ${ }^{1}$ Oregon State University College of Forestry \\ ${ }^{2}$ Oregon State University College of Liberal Arts \\ ${ }^{3}$ Oregon State University
}

November 17, 2021

\begin{abstract}
In U.S. academic institutions, efforts often concentrate on enhancing the recruitment of students from underrepresented groups, focusing on gender and/or race. Yet, non-demographic forms of diversity have received little attention, such as environmental worldviews, i.e., differences in the metaphysical, epistemological, and ethical beliefs that define how humans view, value, and interact with the natural world. Here, we develop an exploratory measure of environmental worldview diversity among undergraduate students enrolled in natural resource related programs. We tested our procedure at Oregon State University, a large public land-grant university in the US. Many students reported metaphysical, epistemological, and/or ethical beliefs that deviate from what has been philosophically characterized as the dominant western worldview of natural resources (anthropocentric, dualistic, hierarchical, utilitarian, mechanistic). Our results suggest that, although forestry students' environmental worldviews are in some ways more closely aligned with the dominant western worldview than other students in natural resources, generally their worldviews reflect long-term generational shifts away from a strict resource-commodity value orientation, as documented in past research. Our findings highlight the importance of considering environmental worldviews as a dimension of diversity within the new generation natural resource students. Future efforts toward understanding these levels of difference can be important assets in designing programs which appeal to wide variety of students; ultimately helping efforts to recruit and retain a diverse of aspiring natural resource professionals.
\end{abstract}

\section{Introduction}

Increasing diversity among students in natural resources (NR) is an expressed goal for many institutions of higher education in the U.S. (ESA 1993, 2006, NSF 2008, OSU CoF 2017). Efforts focus largely on demographic forms of diversity, such as race and gender. These efforts are motivated partially by the recognition that demographically diverse people are likely to have different values, ideas, beliefs, and perspectives (Page 2008), and such non-visible forms of diversity are important as well. In this regard, the goal is to increase both demographic diversity and what we might call "worldview diversity."

But what, precisely, do we mean when we use the word "worldview?" Our conceptualization reflects a philosophical approach that breaks worldviews into three major dimensions: metaphysics (i.e., beliefs about the fundamental nature and structure of the world), epistemology (i.e., beliefs about knowledge and how it is produced), and ethics (i.e., beliefs about what is good and how humans ought to behave). Although it is useful to separate these for analytical purposes (Figure 1), the three dimensions are closely related. For instance, metaphysical beliefs about how the world is, influence ethical beliefs about how humans ought to act; and ethical beliefs about how humans ought to act are informed by epistemological beliefs about how we arrive at moral knowledge or understanding. Especially salient to NR are environmental worldviews, i.e., the metaphysical, epistemological, and ethical beliefs that influence how people view, value, and interact with the natural environment (Mathews 1991, Callicott 1994). 
With "worldview" defined, we next consider what constitutes worldview diversity in NR. The dominant worldview of NR in Eurocentric Western societies has traditionally been 1) anthropocentric (i.e., only humans have direct moral standing); 2) dualistic (i.e., humans are separate from nature; 3) hierarchical (i.e., humans are above nature); 4) utilitarian (i.e., nature should be used for its instrumental benefits); and 5) mechanistic (i.e., nature can be known objectively through reductive, empirical scientific inquiry) (Mathews 1991, Plumwood 1993, Callicott 1994, Xu and Bengston 1997, Crist 2019). Worldview diversity, then, involves representation of people whose worldviews deviate from the dominant NR worldview along one or more dimensions. For example, an alternative worldview might include non-utilitarian and non-anthropocentric beliefs that nature should be honored as kin, and recognized as a sacred community whose value surpasses what it provides for humans (Kimmerer 2013). Worldview diversity would be increased if people with both utilitarian anthropocentric and "kincentric," non-anthropocentric perspectives were represented in NR (Salmon 2000; Bhattacharya and Slocombe 2017).

Demographic information has been closely tracked to monitor diversity trends in NR over time (Sharik et al. 2015, Arismendi and Penaluna 2016, Bal and Sharik 2019). For example, research shows that gender and racial diversity have increased in some areas of environmental sciences and NR fields, although in some of the most traditional fields such as fisheries (Arismendi and Penaluna 2016), aquatic sciences (Abernethy et al. 2020), and forestry (Bal and Sharik 2019) the demographic composition has been slower to change. Overall, though, environmental worldviews are not a commonly measured metric of diversity. As such, while there is a large amount of data on demographic diversity in undergraduate NR programs, the status of and trends in worldview diversity remain less clear.

One reason why worldview diversity has not been regularly assessed may relate to the complexity of the "worldview" concept, which necessitates measurement tools informed by interdisciplinary insights. Therefore, our objectives in the present study were to develop an exploratory measure of worldview diversity in NR; and to assess, in a small-scale study, whether a reputed undergraduate forestry program differs from nonforestry NR programs in terms of worldview diversity. In line with reported lags in demographic diversity in undergraduate forestry programs (Bal and Sharik 2019), we hypothesized that worldview diversity would be similarly resistant to change among forestry students, compared to students in other NR majors.

\section{Methods}

We administered an online survey to a sample of Oregon State University undergraduate students recruited from NR-related courses during the 2017-2018 academic year. A total of 260 students from a variety of majors completed the survey; 218 responses were used for analysis based on their completion of the survey in its entirety (Table 1). Approximately $21 \%(\mathrm{n}=45)$ were forestry majors, which approximates their percentage among natural-resource-related areas of study nationally (Sharik et.al 2015). The survey consisted of 40 questions, but only a subset of these were used for the present analysis.

To measure the ethical/metaphysical elements of environmental worldviews, we used 11 Likert-type items drawn from three established scales, including the New Environmental Paradigm scale (Dunlap et al. 2000), the Connectedness to Nature scale (Mayer and Frantz 2004), and the Environmental Identity scale (Olivos and Aragonés 2011). None of the psychological constructs these scales were designed to measure fully encompasses the philosophical worldview construct, as we conceptualize it, and in appropriating items from these scales it was not our intent to measure the New Ecological paradigm, nature connectedness, or environmental identity, per se. Rather, we chose select items from these scales because they were also suitable to measure certain (ethical and metaphysical) content of the environmental worldview construct; and because, as tested and widely-used survey items, we were confident that they were clearly worded and so had minimal likelihood of generating response error. Items were rated from 1 to 5 (strongly disagree to strongly agree). To group these items for analysis we used principal components factor analysis with a varimax rotation, retaining only variables with loadings of 0.40 or higher and eigenvalues greater than 1.0 (Kaiser 1974). This procedure returned three factors, which we labeled Moral Inclusion (MI), Bond with Nature (BN), and Human's Role (HR) (see Appendix). 
Internal reliability, measured using Cronbach's alpha (Vaske 2008), was acceptable for all three factors (MI: $\alpha=0.77$; BN: $\alpha=0.60$; HR: $\alpha=0.56$ ), so we averaged the scores of items loading on each factor.11One item was removed from the HR score to improve reliability. This produced three composite scores for each student, with lower scores signifying more anthropocentric (MI), more dualistic (BN), and more hierarchical (HR) beliefs. We calculated overall MI, BN, and HR means for forestry and non-forestry students, and compared them using independent sample Student's t-tests (Table 2).

To capture ethical/epistemological aspects of environmental worldviews, we developed a measure to assess the extent to which students deviate from the dominant utilitarian mode of moral reasoning. "Moral reasoning" refers to the reasons people invoke to explain how they believe they ought to behave. We presented five statements, asking students to indicate the extent to which they agreed (or not) that each expresses an appropriate way to approach an environmental decision (Table 3). Items were inspired by five ethical theories identified in the environmental ethics literature (see Des Jardins 2001, Nelson and Vucetich 2012), each representing a different mode of moral reasoning. According to natural law theory, what is natural is good, and should therefore be maintained. Rights of nature refers to the idea nature has certain moral rights, which humans should uphold. Utilitarianism suggests humans should interact with the environment in ways that maximize benefits.22Although the item allowed a non-anthropocentric interpretation, we expect most students interpreted "benefit" in anthropocentric terms. According to virtue theory, humans should manifest certain virtues, such as care and humility, when they interact with the environment. Finally, in divine command theory, humans should interact with the environment as commanded by a divine figure. Students rated each statement on a 0-100 sliding scale, where 0 signifies neutrality and 100 signifies full agreement (Table 3).

Although we piloted this measure informally among colleagues, we acknowledge this was a highly exploratory section of the survey, which is a limitation of the study. Based on suggestive evidence generated from this measure, reported below, we highlight the development and validation of a measure of environmental moral reasoning as a direction that merits attention in future research. For analysis, we used independent t-tests to compare mean utilitarianism ratings between forestry and non-forestry students. We also calculated the proportion of students who rated utilitarianism higher than or equivalent to other modes of moral reasoning for both groups, and compared these proportions using chi-square tests (Figure 2).

A final epistemology measure assessed perceptions of non-scientific (i.e., creative, artistic, philosophical) ways of knowing. We used Likert-type items developed by Goralnik et al. (2015), to have students rate a statement about the value of the humanities. A standard definition of the humanities was included for reference (Stanford Humanities Center:http://shc.stanford.edu/what-are-the-humanities). Survey items were scored from 1 to 5 (strongly disagree to strongly agree). To group the items, we used principal components analysis, following the specifications noted above. All five items loaded on a single factor, which we call Attitudes toward Humanities (AH). Internal reliability was good $(\alpha=0.88)$, so we averaged the five item scores, producing one composite measure for each student (Vaske 2008). Higher scores correspond to more positive attitudes toward the humanities, suggesting students acknowledge the legitimacy of forms of knowledge other than the Western scientific approaches that have generally dominated in NR fields. We averaged AH scores for forestry and non-forestry students, and compared the two groups using independent sample Student's t-tests. Students were also asked whether they want their academic program to incorporate the humanities (yes/no/unsure). We used chi-square to compare "yes" versus "no/unsure" responses between forestry and non-forestry students (Figure 3).

\section{Results}

The metaphysical/ethical dimensions of worldviews (anthropocentrism, dualism, hierarchy) differed by major (Table 2). On average, forestry students scored lower (indicating stronger dominant views) on MI (anthropocentrism) and HR (hierarchy) than non-forestry students. Both differences were statistically significant, and relationships between major and the measures were moderately strong for MI and very strong for HR. We also found a moderately strong, statistically significant relationship between major and mean BN (dualism) ratings, with forestry students on average rating BN higher than non-forestry students (indicating less 
dominant views).

For the ethics/epistemology dimension of worldviews (modes of moral reasoning), we found similarities and differences between majors (Table 3). Virtue was rated highest by both forestry and non-forestry students, while divine command was rated lowest by both forestry and non-forestry students. However, whereas utilitarianism received the second-lowest ratings among non-forestry students, it received the second-highest ratings among forestry students. There was also a strong, statistically significant relationship between major and mean utilitarianism ratings (Table 2), and a higher percentage of forestry than non-forestry students rated utilitarianism as their preferred mode of moral reasoning (Figure 2).

For our final epistemology measure (attitudes toward humanities), the sample overall reported favorable attitudes toward the humanities. However, mean AH scores were lower among forestry than non-forestry students. The difference in AH scores was statistically significant (Table 2). The percentage of forestry students who would like the humanities in their program was lower than the percentage of non-forestry students, but this difference was not statistically significant (Figure 3).

\section{Discussion}

Overall, our sample endorsed many elements of a non-dominant environmental worldview. Both forestry and non-forestry students generally affirmed the non-anthropocentric belief that some parts of nature have intrinsic value and direct moral standing, and endorsed the non-dualistic belief that humans are part of the natural world. However, whereas non-forestry students generally rejected the idea that humans dominate over nature, forestry students generally accepted this idea. In this regard, forestry students largely aligned with the dominant Eurocentric Western view that humans are at the top of a hierarchy over nature.

Among all students, virtue was the most highly rated mode of moral reasoning, suggesting students do not only see environmental decision-making as a calculation of benefits relative to costs. Nonetheless, forestry students did strongly endorse utilitarian reasoning, and more forestry than non-forestry students indicated utilitarianism as their preferred mode of moral reasoning.

On the whole, although forestry students are in some ways more strongly aligned with a dominant environmental worldview than non-forestry students, we suggest this is better understood as a difference of degree, rather than kind. Our findings corroborate with past research demonstrating generational shifts in forestry away from a strict resource-commodity orientation, and toward an ecosystem perspective emphasizing and valuing the holistic and aesthetic properties of forests (Xu and Bengston 1997, Brown and Harris 2000; Martin and Steelman 2004). The current study can be situated in this body of research, documenting the continuation and ongoing evolution of a trajectory of worldview diversification that initiated several decades ago. However, our study also builds on this work by articulating the characteristics of environmental worldview shift in more detailed philosophical terms.

Forestry students reported slightly less dualistic beliefs than non-forestry students, according to their rating for the BN worldview factor. This was an interesting finding, and replicate studies in other NR settings would be required to determine if this is a stable pattern. By way of explanation, we speculate that the difference may relate to the breakdown of non-forestry majors, which included basic scientific disciplines such as biology and zoology. While students in more applied, interdisciplinary NR majors, including forestry, may have been exposed to non-dualistic discourses, e.g., around socio-ecological systems or human dimensions of natural resources, students in the more basic science programs may have less exposure to these frameworks. This is a hypothesis for testing in future studies.

In an exploratory capacity, this study suggests interesting trends that merit investigation at a broader scale. Our results suggest there is already some worldview diversity in NR at OSU, which inspires the hypothesis that similar diversity might also exist in other undergraduate NR programs. Yet this hypothesis also leads us to question whether current NR programs are set up to support students with diverse worldviews. Enrollments in traditional NR programs, including forestry, have been dropping (Sharik et al. 2015, Bal and Sharik 2019). This may be, in part, because incoming students do not find resonance in the ethical, 
metaphysical, and epistemological orientations of NR programs. Institutionally, NR remains largely aligned with dominant (anthropocentric, dualistic, hierarchical, utilitarian, mechanistic) values and beliefs (Crist 2019). It may be important to consider how NR programs could re-define themselves to remain relevant and attract incoming students.

One strategy might be to increase offerings in the humanities within NR programs. Overall, our sample reported positive attitudes toward the humanities, yet most respondents were unsure or did not want humanities studies as part of their degree program. This finding suggests NR students recognize the value of alternative ways of knowing, but still believe science is sufficient to understand and manage interactions between humans and the environment. This view is not consistent with scholarship suggesting a rich array of disciplinary perspectives is required to address wicked environmental challenges (Allen and Gould 1968, Brown et al. 2010, Balint et al. 2011, Hulme 2011). There are many ways NR programs might be expanded to incorporate the humanities. For example, readings in environmental philosophy, ethics, or history could be integrated into the curricula of introductory, elective, or capstone courses. Programs might also develop short courses or one-credit seminars that feature guest lecturers from humanities programs across campus. By these or other channels, integrating scholarship from the humanities into NR programs may equip students not only to become better environmental problem-solvers, but also to build vocabularies and skills that allow them to express and critically evaluate aspects of both dominant and non-dominant worldviews. In this way, NR programs can create space for, and give voice to, diverse people expressing diverse perspectives.

Finally, students entering NR fields should be appreciated as complex individuals who bring different values, beliefs, and ways of knowing. Programs that do not intentionally create space for diverse perspectives may alienate students who hold alternative values and beliefs, or assimilate them to prevailing institutional norms, thus flattening an important yet often invisible and unacknowledged dimension of diversity (e.g., see discussions in Wolsko et al. 2006, Marvasti and McKinney 2011; also Lee 2019). Educators need to understand the environmental worldviews of their students in order to meet aspiring NR professionals where they are, designing programs that broaden students' horizons while also nurturing their unique beliefs and experiences. We challenge readers to reflect on current diversity efforts, and ask how NR might at once remain committed to reducing social inequities, while also considering invisible but nonetheless critical elements of diversity. We encourage the NR community to broaden its definition of diversity to include environmental worldviews by actively recruiting, retaining, and supporting students who represent diverse worldviews.

\section{Acknowledgments}

This research was supported by the H.J. Andrews Experimental Forest research program, and funded by the National Science Foundation's Long-Term Ecological Research Program under Grant No. DEB-1440409. A special thanks to our colleagues which helped shaped the direction of this project through their advice, creativity and discussions: A. Haley, B. Robertshaw, C. Gallagher, D. Anecito, J. Brown, L. Hadella, M. Walsh, and S. Kelly.

\section{Data Availability Statement}

The data that support the findings of this study will be deposited in Dryad. https://doi.org/xxxx

\section{Literature Cited}

Abernethy, E. F., Arismendi, I., Boegehold, A. G., Colón-Gaud, C., Cover, M. R., Larson, E. I., Moody, E. K., Penaluna, B. E., Shogren, A. J., Webster, A. J., \& Woller-Skar, M. M. (2020). Diverse, equitable, and inclusive scientific societies: Progress and opportunities in the Society for Freshwater Science. Freshwater Science, 39(3), 363-376.

Allen, G.M., and. Gould Jr, E.M. 1968. Complexity, wickedness, and public forests. Journal of Forestry 84(4): 20-23.

Arismendi, I., \& Penaluna, B. E. (2016). Examining Diversity Inequities in Fisheries Science: A Call to Action. BioScience, 66(7), 584-591. 
Bal, T.L., and Sharik, T. 2019 "Web Content Analysis of University Forestry and Related Natural Resources Landing Webpages in the United States in Relation to Student and Faculty Diversity. Journal of Forestry 117(4): 379-97.

Bal, T.L, and Sharik, T. 2019 "Image Content Analysis of US Natural Resources-Related Professional Society Websites with Respect to Gender and Racial/Ethnic Diversity." Journal of Forestry 117(4): 360-64.

Balint, P.J., Stewart,R.E., Desai,A., and Walters,L.C. 2011. Wicked environmental problems: managing uncertainty and conflict. Island Press.

Bhattacharyya, J, and Slocombe,S. 2017. Animal agency: wildlife management from a kincentric perspective. Ecosphere 8(10): e01978.

Brown, G. and Harris, C.C. 2000. The US Forest Service: Whither the new resource management paradigm?. Journal of Environmental Management 58(1): 1-19.

Brown, V.A., Harris, J.A. and Russell, J.Y. eds. 2010. Tackling wicked problems through the transdisciplinary imagination. Earthscan.

Callicott, J.B. 1994. Earth's insights: a multicultural survey of ecological ethics from the Mediterranean Basin to the Australian Outback. Berkeley: University of California Press.

Crist E. 2019. Abundant Earth : Toward an Ecological Civilization. University of Chicago Press.

Des Jardins, J.R. 2001. Environmental Ethics: An Introduction to Environmental Philosophy, $3^{\text {rd }}$ edn. Wadsworth, Belmont, CA.

Dunlap, R.E., Van Liere, K.D, Mertig, A.G., and Jones, R.E. 2000. New Trends in Measuring Environmental Attitudes: Measuring Endorsement of the New Ecological Paradigm: A Revised NEP Scale. Journal of Social Issues 56(3): 425-42.

[ESA] Ecological Society of America. 1993. Mechanisms to Increase Recruitment and Retention of Women and Under-represented Groups in Ecology: Report from the Strategic Planning Workshop" (WAMIE I).

[ESA] Ecological Society of America. 2006. Women and Minorities in Ecology II (WAMIE II): Committee Report.

Goralnik, L., Nelson, M.P., Ryan, L., and Gosnell, H. 2015. Arts and Humanities Efforts in the US Long-Term Ecological Research (LTER) Network: Understanding Perceived Values and Challenges. Earth Stewardship Ecology and Ethics :249-68.

Hulme, M. 2011. Meet the Humanities. Nature Climate Change 1(4): 177-79.

Kaiser, H.F. 1974. An Index of Factorial Simplicity.Psychometrika 39(1): 31-36.

Kimmerer, R.W. 2013. Braiding sweetgrass: Indigenous wisdom, scientific knowledge and the teachings of plants. Milkweed Editions.

Lee, O. 2019. Theme 4: What Does Diversity Require of Us?.Fisheries 44(8): 375-375.

Martin, I.M., and Steelman, T.A. 2004. Using multiple methods to understand agency values and objectives: Lessons for public lands management. Policy Sciences 37(1): 37-69.

Marvasti, A.B., and McKinney, K.D. 2011 "Does diversity mean assimilation?." Critical Sociology 37(5): 631-650.

Mathews, F. 1991. Democracy and the ecological crisis. Legal Service Bulletin. : 157-159.

Mayer, F.S, and Frantz,C. 2004. The Connectedness to Nature Scale: A Measure of Individuals' Feeling in Community with Nature. Journal of Environmental Psychology 24(4). 
Nelson, Michael P., and John A. Vucetich. 2012. Environmental ethics for wildlife management. Human dimensions of wildlife management : 223-237.

[NSF] National Science Foundation. 2008. Broadening participation at the National Science Foundation: A framework for action .

Olivos, P., Aragonés, J. I., \& Amérigo, M. 2011. The connectedness to nature scale and its relationship with environmental beliefs and identity. International Journal of Hispanic Psychology , 4: 5-19.

[OSU CoF] Oregon State University College of Forestry. 2017.Diversity, Equity and Inclusion Strategic Plan

Page, S. E. 2008. The Difference: How the Power of Diversity Creates Better Groups, Firms, Schools, and Societies-New Edition. Princeton University Press.

Phillips, K.W. and Loyd, D.L. 2006. When Surface and Deep-Level Diversity Collide: The Effects on Dissenting Group Members. Organizational Behavior and Human Decision Processes 99(2): 143-60.

Plumwood, V. 1993. The Politics of Reason: Towards a Feminist Logic.Australasian Journal of Philosophy 71(4): 436-62.

Salmón, E. 2000. Kincentric ecology: indigenous perceptions of the human-nature relationship. Ecological Applications 10(5): 1327-1332.

Sharik, T.L., Lilieholm, R.J., Lindquist W, and Richardson,W.W. 2015. Undergraduate Enrollment in Natural Resource Programs in the United States: Trends, Drivers, and Implications for the Future of Natural Resource Professions. Journal of Forestry 113(6): 538-51.

Vaske, J. 2008. Survey Research and Analysis: Applications in Parks, Recreation, and Human Dimensions . State College, PA: Venture Publications.

Wolsko, C., Park, B., and Judd. C.M. 2006. Considering the tower of Babel: Correlates of assimilation and multiculturalism among ethnic minority and majority groups in the United States. Social Justice Research 19(3): 277-306.

Xu. Z., and D. N. Bengston. 1997. Trends in national forest values among forestry professionals, environmentalists, and the news media, 1982-1993. Society and Natural Resources 10: 43-59. 


\section{Basic Worldview Model}

Epistemology Metaphysics

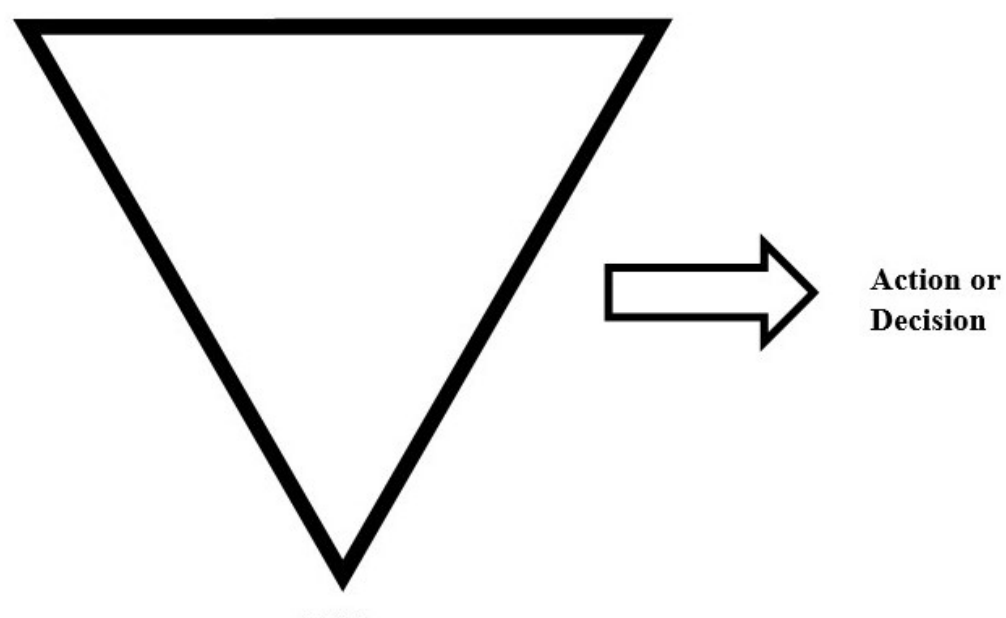

Ethics

Figure 1. Basic Worldview Model- This figure contains the basic elements that make up a worldview: epistemology, ethics, and metaphysics, which ultimately influence actions or decisions.

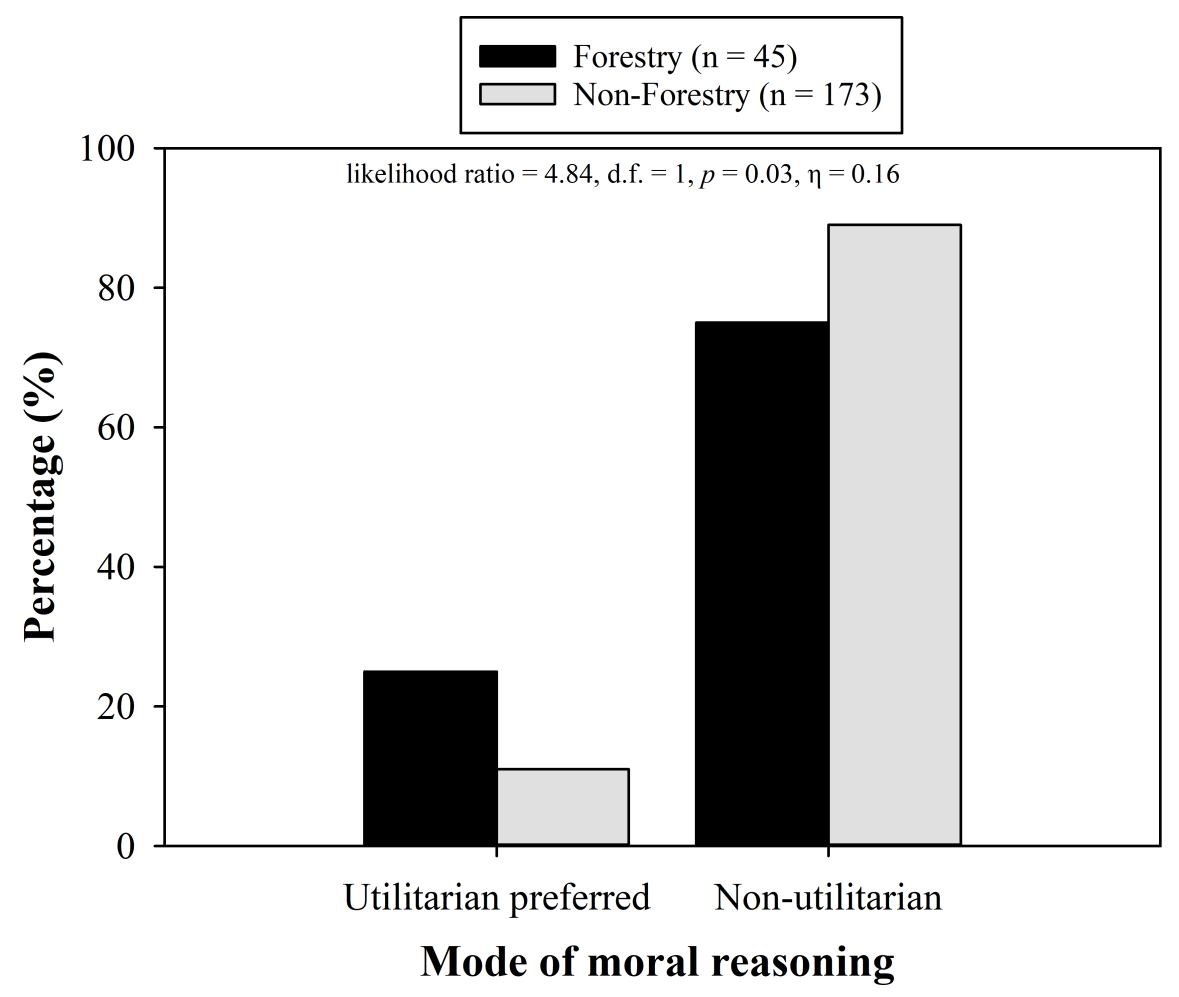




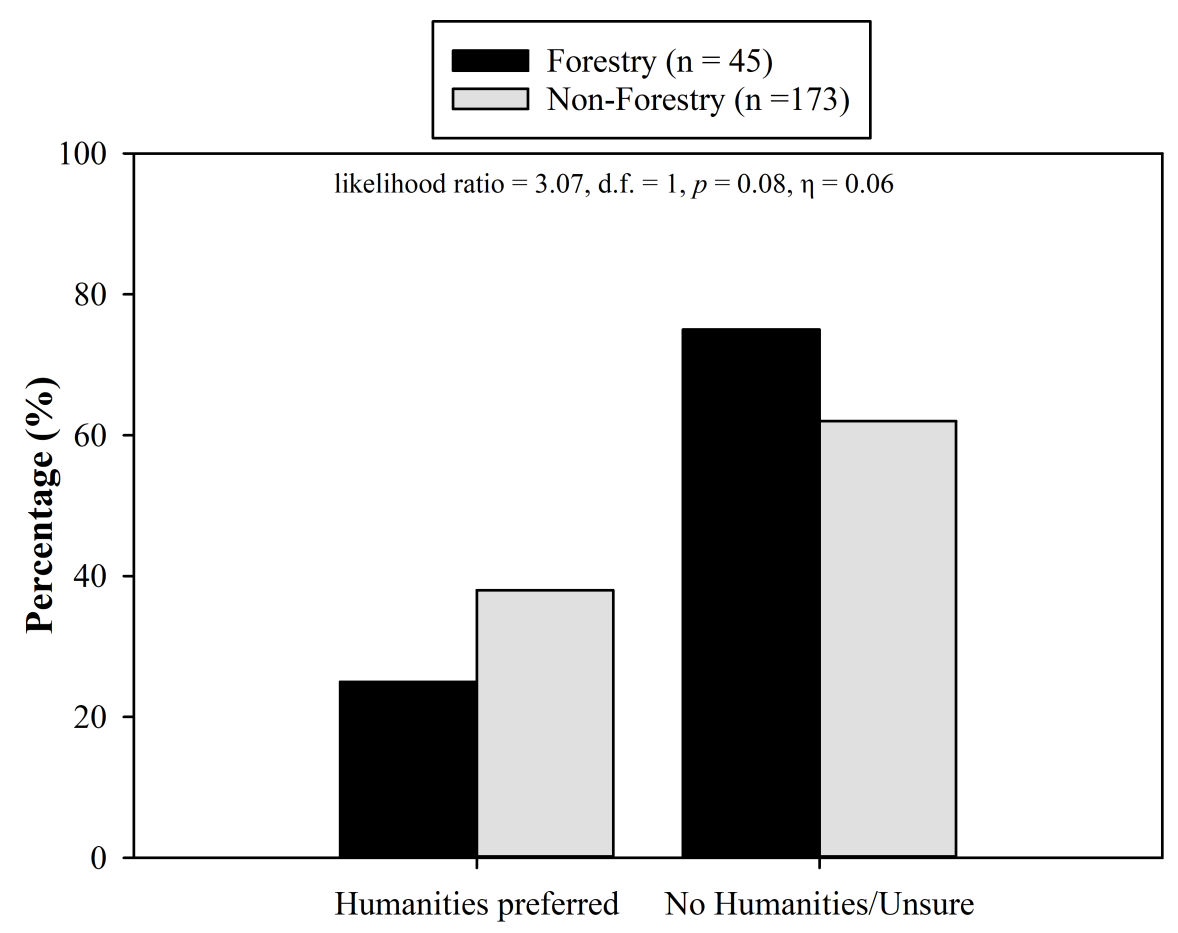

Would like humanitities in their program

\section{Hosted file}

Table 1.docx available at https://authorea.com/users/446704/articles/545874-diversity-beyonddemographics-environmental-worldviews-of-forestry-and-natural-resource-undergraduatestudents

\section{Hosted file}

Table 2.docx available at https://authorea.com/users/446704/articles/545874-diversity-beyonddemographics-environmental-worldviews-of-forestry-and-natural-resource-undergraduatestudents

\section{Hosted file}

Table 3.docx available at https://authorea.com/users/446704/articles/545874-diversity-beyonddemographics-environmental-worldviews-of-forestry-and-natural-resource-undergraduatestudents

\section{Hosted file}

Appendix.docx available at https://authorea.com/users/446704/articles/545874-diversitybeyond-demographics-environmental-worldviews-of-forestry-and-natural-resourceundergraduate-students 